\title{
QUALIDADE FISIOLÓGICA E SANITÁRIA DAS SEMENTES SOB SEMEADURA ANTECIPADA DA SOJA
}

\author{
PHYSIOLOGICAL AND SANITARY QUALITY OF SEEDS UNDER TO EARLY \\ SOYBEAN SOWING
}

\author{
Leandro Paiola ALBRECHT ${ }^{2}$ \\ Alessandro de Lucca e BRACCINI ${ }^{3}$ \\ Carlos Alberto SCAPIM ${ }^{4}$ \\ Celso Gonçalves de AGUIAR ${ }^{5}$ \\ Marizangela Rizzatti ÁVILA ${ }^{6}$ \\ Marcibela STÜLP ${ }^{7}$
}

\begin{abstract}
RESUMO
A semeadura antecipada da soja, particularmente com cultivares precoces, é prática que vem sendo adotada por muitos produtores paranaenses com o intuito de antecipar a colheita da cultura e viabilizar o cultivo de milho safrinha. Com o objetivo de avaliar a influência da antecipação da semeadura na qualidade fisiológica e sanitária das sementes de soja, foram instalados ensaios de competição de cultivares na unidade da COODETEC, em Palotina, PR. O delineamento foi em blocos casualizados, conduzido em duas safras (2003/2004 e 2004/2005), com três cultivares precoces (CD 202, CD 215 e CD 216), semeadas em cinco épocas (15/09, 30/09, 15/10,30/10 e 15/11). A qualidade fisiológica das sementes de soja foi avaliada por meio dos testes de germinação (primeira contagem e contagem final) e de tetrazólio (vigor e viabilidade). O "blotter test" foi aplicado para caracterizar a sanidade das sementes. Os dados coletados foram submetidos à análise de variância conjunta e realizados os desdobramentos das interações quando necessários. Os resultados obtidos indicaram que a semeadura em $30 /$ 10 foi favorável à obtenção de sementes com melhor qualidade.

Palavras-chave: Glycine max; época de semeadura; germinação e vigor.
\end{abstract}

\begin{abstract}
An early soybean sowing, especially early maturing varieties is a practice that has been adopted by many growers in the state of Paraná in order to anticipate the harvest of the crop and enhance the fall corn. For this reason, experiments of corn cultivar competition trials were carried out at COODETEC in the county of Palotina, Paraná State, to evaluate the influence of the early sowing on the quality of soybean seeds produced. A randomized block design, during two harvests (2003/2004 and 2004/2005); three early maturing varieties (CD 202, CD 215 and CD 216); and five sowing dates (09/15, 09/30, 10/15, 10/ 30 and 11/15) were utilized. The physiological trait of soybean seeds was evaluated by the germination test (first and final count); and tetrazolium (vigor and viability) tests. The blotter test was used to evaluate sanitary quality of the seeds. The data were submitted to variance analysis between groups along with all necessary adjustments. The results showed that the sowing dates $30 / 10$, was favorable for the production of seeds with better quality.
\end{abstract}

Key-words: Glycine max; sowing date; germination and vigor.

\footnotetext{
${ }^{1}$ Dados que compõe parte de uma Dissertação de Mestrado em Agronomia, aprovada na Universidade Estadual de Maringá, em julho de 2006, Maringá - PR.

2 Engenheiro Agrônomo, Mestre em Agronomia, Bolsista do CNPq, Acadêmico do Doutorado em Agronomia da Universidade Estadual de Maringá, Maringá (PR). Email: Ipalbrecht@yahoo.com.br

${ }^{3}$ Engenheiro Agrônomo, Doutor em Fitotecnia, Professor Adjunto da Universidade Estadual de Maringá, Av. Colombo, 5790, Maringá, PR, CEP 87020-900, Maringá (PR). Email: albraccini@uol.com.br. Autor para correspondência.

${ }^{4}$ Engenheiro Agrônomo, Doutor em Fitotecnia, Professor Adjunto da Universidade Estadual de Maringá, Maringá (PR). Email: cascapim@uem.com.br

${ }^{5}$ Eng. Agrônomo, Dr., Pesquisador da Cooperativa Central de Pesquisa Agrícola (COODETEC), BR 467, Km 98, Cx. Postal 301, Cascavel, PR, CEP 85813-450; Email: aguiar@coodetec.com.br

${ }^{6}$ Engenheira Agrônoma, Doutora em Agronomia, Professora Adjunta da Universidade Estadual de Maringá, Maringá (PR). Email: marizangela_rizzatti@hotmail.com

7 Engenheira Agrônoma, Mestre em Agronomia, Professora Assistente da Universidade Estadual de Maringá, Maringá (PR). Email: marcibela@terra.com.br
} 


\section{INTRODUÇÃO}

Dada a sua importância, a cultura da soja tem apresentado intensa atividade de pesquisa dirigida à obtenção de informações que possibilitem aumentos na produtividade e redução nos custos de produção (EMBRAPA, 2003). A soja está sujeita a uma gama de alterações fisiológicas e morfológicas, quando as suas exigências não são satisfeitas (BONATO et al., 1998; EMBRAPA, 2003). Em qualquer lugar que as plantas cresçam, estarão sujeitas às condições de múltiplos estresses, os quais limitarão seu desenvolvimento e suas chances de sobrevivência (TAIZ e ZEIGER, 2004). As atipicidades na questão climática, em áreas agricultáveis do Brasil, encontram-se sob a influência de fenômenos como o La Niña e o El Niño, entre outros, eventualmente (BERLATO e FONTANA, 1999).

Considerando que a cultura da soja é influenciada por diversos fatores ao longo de seu ciclo, é relevante destacar a escolha da época de semeadura, como sendo o fator cultural, que isoladamente mais influência o desenvolvimento das plantas e a produção da lavoura e, também, a qualidade das sementes. A influência do ambiente no desenvolvimento da semente é traduzida, principalmente, por variações no tamanho, peso, qualidade fisiológica e sanidade (PAOLINELLI et al., 1984; BHÉRING et al., 1991; COSTA et al., 1995; PEIXOTO et al., 2000; PEREIRA et al., 2000; MOTTA et al., 2002; BARROS et al., 2003; EMBRAPA, 2003; MARCOS FILHO, 2005; PELÚZIO et al., 2006; SILVA et al., 2007).

O período preferencial para a semeadura da soja no Estado do Paraná é o mês de novembro, porém, a época de semeadura indicada, para a maioria das cultivares, estende-se de $15 / 10$ a $15 / 12$ (EMBRAPA, 2003). A antecipação da semeadura, segundo a EMBRAPA (2003) é a semeadura realizada antes de 15 de outubro. Pode ser praticada em regiões mais quentes do Estado, onde ocorre inverno úmido, solos de alta fertilidade $e$ temperaturas favoráveis à emergência das plantas desde o início de outubro. Estas condições são mais comuns na Região Oeste do Paraná, nas áreas de menor altitude, mais próximas do Rio Paraná, localizadas entre o Rio Piquiri e Iguaçu.

O objetivo do trabalho foi avaliar a influência da antecipação da semeadura na qualidade fisiológica e sanitária das sementes de três cultivares precoces de soja, em dois anos agrícolas.

\section{MATERIAL E MÉTODOS}

A presente pesquisa foi conduzida nos anos agrícolas de 2003/2004 e 2004/2005, em área localizada na Unidade da Cooperativa Central de Pesquisa Agrícola (COODETEC), em Palotina - PR

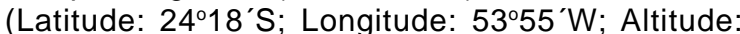
$310 \mathrm{~m}$; Classe do Solo: Latossolo Vermelho Eutroférrico, A moderado, textura muito argilosa), local em que foi conduzida a parte experimental, de campo. No Laboratório de Tecnologia de Sementes do Núcleo de Pesquisas Aplicadas à Agricultura (NUPAGRI), pertencente à Universidade Estadual de Maringá, em Maringá - PR, foram realizados os testes de avaliação da qualidade das sementes.

O clima predominante na região é do tipo Cfa, mesotérmico úmido, com chuvas abundantes no verão e inverno seco, e verões quentes, segundo classificação de Köppen. Foram coletados dados diários de precipitação pluvial e temperatura máxima e mínima, referentes aos períodos de duração dos ensaios, anos agrícolas de 2003/2004 e 2004/2005.

Foram instalados cinco ensaios de competição de cultivares, com três tratamentos e quatro repetições, semeando-se um ensaio em cada época de plantio (15/09, 30/09, 15/10, 30/10 e $15 / 11)$. As três cultivares de soja avaliadas foram CD 202, CD 215 e CD 216, todas pertencentes ao grupo de maturação precoce (COODETEC, 2005).

O sistema de preparo do solo adotado foi a semeadura direta e, a adubação e todas as demais práticas culturais foram as preconizadas pelo sistema de produção da região (EMBRAPA, 2003). Quanto a semeadura, foram deixados cerca de 16 plantas por metro linear (densidade de 355.555 plantas $\mathrm{ha}^{-1}$ ), a fim de padronizar o estande. A irrigação por aspersão foi fornecida somente logo após a semeadura da soja para garantir o estabelecimento inicial das plantas. A área útil das unidades experimentais foi de $7,2 \mathrm{~m}^{2}$.

As plantas foram colhidas manualmente, cinco a oito dias após o estádio $R_{8}$ de desenvolvimento (FEHR et al., 1971), quando as sementes de soja apresentavam grau de umidade abaixo de $15 \%$ (base úmida). Após a colheita das plantas, as sementes de soja foram debulhadas das vagens em máquina trilhadeira estacionária, limpas com o auxílio de peneiras, secadas em condições naturais, acondicionadas em sacos de papel kraft multifoliado e mantidas em câmara fria, a $10{ }^{\circ} \mathrm{C}$ de temperatura e $50 \%$ de umidade relativa, do final da colheita ao início das avaliações de laboratório pelos seguintes testes.

Teste de germinação: foi realizado com quatro subamostras de 50 sementes para cada tratamento e repetição de campo. Para instalação e condução do teste foram adotados procedimentos descritos nas Regras para Análise de Sementes (BRASIL, 1992). Os resultados foram expressos em porcentagem de plântulas normais.

Primeira contagem do teste de germinação: foi efetuada em conjunto com o teste de germinação, computando-se a porcentagem de plântulas normais obtidas no quinto dia após a semeadura (BRASIL, 1992).

Teste de tetrazólio: para o teste utilizou-se 100 sementes (duas subamostras de 50 sementes) para cada tratamento e repetição de campo. Foram seguidas as prescrições de FRANÇA NETO e HENNING (1992) e FRANÇA NETO et al. (1998). Na avaliação as sementes foram classificadas quanto ao vigor e viabilidade em níveis de 1 a 8 , segundo os critérios propostos por FRANÇA NETO et al. (1998). 
Teste de sanidade: efetuado por meio do método do papel-filtro, utilizando-se 100 sementes, divididas em cinco subamostras de 20 para cada tratamento e repetição de campo e colocadas em caixas plásticas $(11,0 \times 11,0 \times 3,5 \mathrm{~cm})$, sobre quatro folhas de papel-filtro esterilizadas e umedecidas com água destilada e autoclavada. A incubação foi realizada em condição ambiente de laboratório, à temperatura de aproximadamente $25^{\circ} \mathrm{C}$, em regime de $12 \mathrm{~h}$ de iluminação com lâmpadas fluorescentes, alternadas com $12 \mathrm{~h}$ de escuro, durante sete dias. Após esse período, foram avaliados os fungos presentes nas sementes, com o auxílio de lupa com iluminação e microscópio estereoscópio (FRANÇA NETO e HENNING, 1992; GOULART, 1997).

O delineamento experimental foi em blocos completos casualizados com quatro repetições de campo, em que cada época de semeadura foi constituída de ensaio individual de competição de cultivares de soja, em dois anos agrícolas. Os dados obtidos para todas as variáveis em cada um dos ensaios individuais, para os dois anos, foram submetidos à análise de variância conjunta. Verificou-se a semelhança dos quadrados médios do resíduo pelo Teste de Hartley e, a razão entre o maior e o menor quadrado médio residual, para proceder a análise de grupos de experimentos (PIMENTEL-GOMES e GARCIA, 2002).

Houve no ensaio, a existência de efeitos fixos (cultivar e época) e efeitos aleatórios (ano). Foram calculadas as esperanças do quadrado médio - $E(Q M)$ - conforme modelo biométrico adotado e, segundo pressupostos de CRUZ et al. (2004). Independente da significância pelo teste $F$ $(p<0,05)$, na interação de segunda ordem (tripla: ano $x$ época $x$ cultivar), prosseguiu-se os desdobramentos necessários para diagnosticar possíveis efeitos da interação.

As médias foram comparadas pelo teste de Newman Keuls $(P<0,05)$, para avaliação dos efeitos de cultivares dentro de cada época e ano. Enquanto que a comparação entre anos, para cultivares, dentro de épocas, o próprio teste $F$ foi conclusivo. $A$ análise de regressão foi realizada para verificar o comportamento das variáveis em função das épocas de semeadura, para cada cultivar, dentro dos anos.

\section{RESULTADOS E DISCUSSÃO}

Os dados climáticos, coletados nos anos agrícolas de 2003/2004 e 2004/2005, encontramse na Figura 1. Os dados de temperatura obtidos durante o período de condução do experimento tenderam a ser superiores ao histórico da região (IAPAR, 2006), em especial 2004/2005, com média térmica e picos de máxima superiores, marcadamente nos últimos meses de condução do experimento.

Os ambientes mais favoráveis à produção de sementes de soja de melhor qualidade fisiológica são aqueles com temperatura média inferior a $22^{\circ} \mathrm{C}$ (COSTA et al., 1994; MARCOS FILHO, 2005). Todos os meses, com exceção do mês de setembro, para os dois anos agrícolas, tiveram temperaturas médias, por decêndio, superiores a $22^{\circ} \mathrm{C}$, sendo os meses de janeiro, fevereiro e março os que apresentaram temperaturas médias mais elevadas, girando em torno dos $25,5^{\circ} \mathrm{C}$. Por exemplo, a temperatura média do ar mensal para os meses de janeiro, fevereiro e março de 2005 foram, respectivamente, de 25,$2 ; 25,0$ e $25,5{ }^{\circ} \mathrm{C}$ (IAPAR, 2006).

A ocorrência de precipitação foi relativamente baixa durante o período de execução do experimento, para ambos os anos agrícolas. Para o ano agrícola de 2003/2004, a média mensal foi de $111 \mathrm{~mm}$ e o total no período de $777 \mathrm{~mm}$. Para o ano agrícola 2004/2005, a média mensal e o acumulado em $\mathrm{mm}$ foi superior a 2003/04, sendo respectivamente, de 120 e $846 \mathrm{~mm}$. A restrição hídrica no ano agrícola 2003/2004 (primeiro), foi mais acentuada em alguns meses, enquanto que, para 2004/2005 (segundo), o déficit hídrico ocorreu, mas não foi tão crítico, pois esteve disperso por mais meses, sendo assim, atenuado o seu efeito negativo.

A porcentagem de plântulas normais, em média, na primeira contagem (indicativo de vigor) e contagem final (indicativo de viabilidade) do teste de germinação (Tabela 1 ), indicou que o segundo ano agrícola do experimento (2004/2005) não proporcionou a obtenção de sementes de qualidade fisiológica superior ao primeiro ano agrícola. Para a quarta e quinta época de semeadura, a cultivar CD 202 foi a única que apresentou média significativamente inferior $(P<0,05$, pelo teste $F)$, em ambas as avaliações do teste de germinação para o primeiro ano agrícola do experimento (2003/2004), em relação ao segundo ano, sinalizando uma resposta diferencial quanto ao conjunto de resultados das épocas anteriores (15/09, 30/09 e 15/10).

O fato supramencionado repete-se no teste de tetrazólio para potencial de vigor (Tabela 2). Atribuído à restrição hídrica ocorrida em um decêndio (terceiro do mês de fevereiro), que foi mais severa no primeiro ano do que no segundo ano agrícola. No teste de tetrazólio (Tabela 2), as sementes das cultivares CD 215 e CD 216 apresentaram performance superior no segundo ano, quando comparado ao primeiro ano, isso para a quinta época de semeadura. Na quarta época, para todas as cultivares produzidas no primeiro ano, a qualidade das sementes foi inferior. Provavelmente a restrição hídrica ocorrida no mês de janeiro do primeiro ano agrícola, mais severa do que no segundo ano, em plena fase reprodutiva para as cultivares semeadas na quarta e quinta épocas, associada às altas temperaturas observadas, afetou negativamente a qualidade das sementes (Figura 1). 

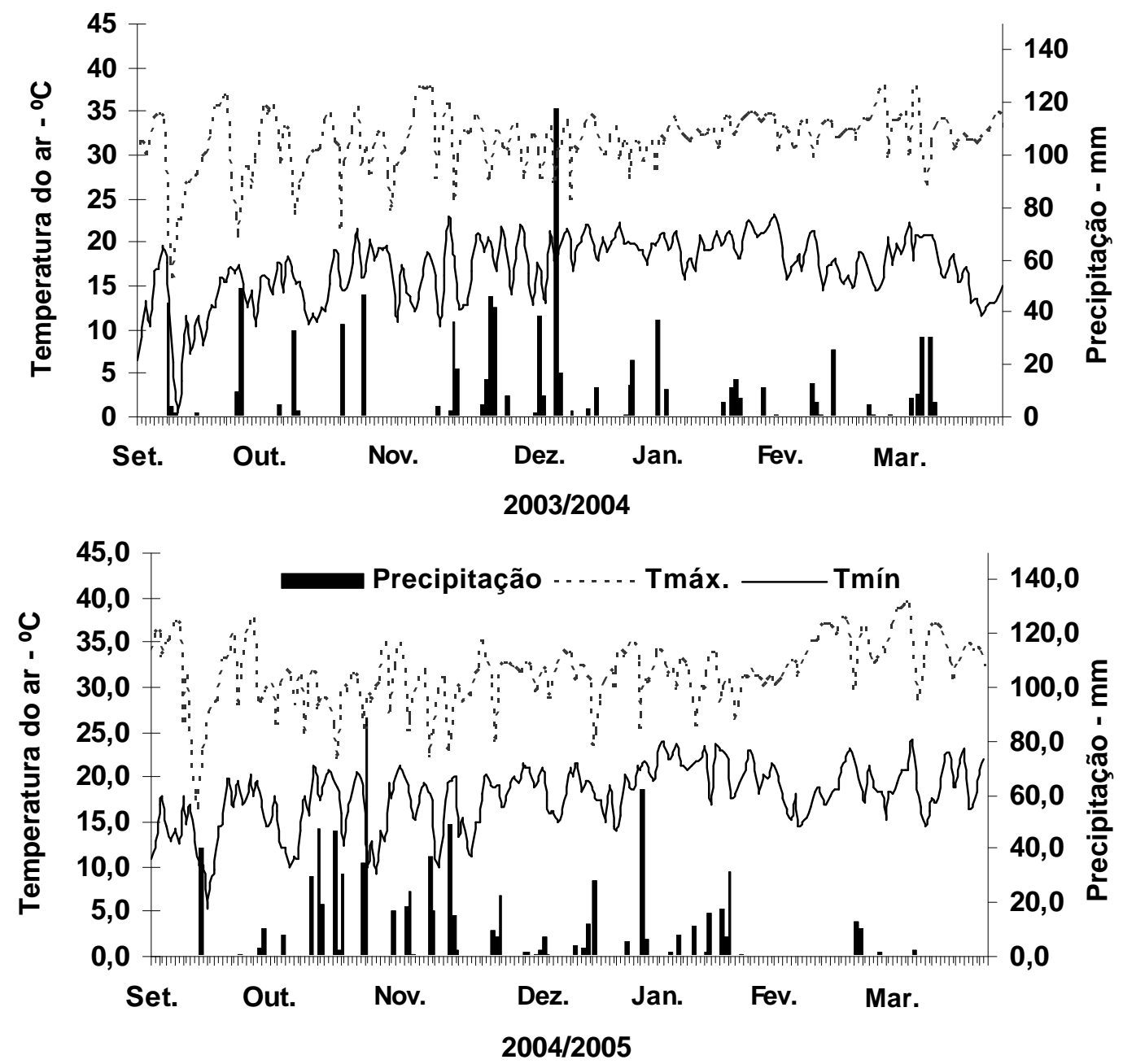

Precipitação

Tmáx. Tmín

FIGURA 1 - Temperaturas médias de máxima e mínima e precipitação pluvial, em Palotina, Estado do Paraná, de setembro a março dos anos agrícolas de 2003/2004 e 2004/2005. Fonte: IAPAR (2006).

A menor disponibilidade de água promove decréscimo da fotossíntese e abrevia o período de enchimento das sementes, com prejuízo à produção (BERLATO e FONTANA, 1999; MATZENAUER et al., 2003; MATZENAUER et al., 2005) e a qualidade de sementes (BRADFORD, 1994; MARCOS FILHO, 2005). A escassez ou o excesso hídrico e a elevação da temperatura, por exemplo, causam distúrbios à formação da semente (FRANÇA NETO et al., 1993; MARCOS FILHO, 2005), pois afeta o metabolismo, acarretando menor suprimento de assimilados e prejudica o crescimento das plantas, o rendimento e a qualidade das sementes (BRADFORD, 1994; BERGAMIN et al., 1999). Os efeitos nocivos da associação estresse por calor e o choque térmico, se acentuam quando associados à deficiência hídrica (TAIZ e ZEIGER, 2004; MARCOS FILHO, 2005).

De acordo com as normas de produção de sementes vigentes no Brasil (BRASIL, 2005), a germinação mínima aceitável é de $80 \%$ para as categorias C1 e C2 das sementes certificadas. $\mathrm{O}$ padrão para semente certificada não foi alcançado nos dois anos para a maioria das cultivares dentro da maioria das épocas de semeadura. No entanto, o padrão para semente básica foi atingido para praticamente todas as cultivares em quase todas as épocas de semeadura. A porcentagem de germinação superior a $65 \%$ demonstrou aptidão da região de Palotina à produção de sementes genética e básica de soja (BRASIL, 2005) em determinados períodos e para determinadas cultivares. 
ALBRECHT, L.P. et al. Qualidade fisiológica e sanitária das sementes...

TABELA 1 - Porcentagens de plântulas normais obtida na primeira contagem e na contagem final do teste de germinação das sementes de três cultivares de soja, produzidas em cinco épocas de semeadura, nos anos agrícolas de 2003/2004 e 2004/2005, em Palotina - PR.

\begin{tabular}{|c|c|c|c|c|}
\hline \multirow{3}{*}{ Cultivar $^{1}$} & \multirow{2}{*}{\multicolumn{2}{|c|}{$\frac{1^{\text {a }} \text { contagem do Teste de Germinação }}{\text { Ano agrícola }{ }^{2}}$}} & \multirow{2}{*}{\multicolumn{2}{|c|}{$\begin{array}{c}\text { Contagem final do Teste de Germinação } \\
\text { Ano agrícola }{ }^{2}\end{array}$}} \\
\hline & & & & \\
\hline & $2003 / 04$ & $2004 / 05$ & $2003 / 04$ & $2004 / 05$ \\
\hline \multicolumn{5}{|c|}{$15 / 09$} \\
\hline CD 202 & $48,87 \mathrm{Ba}$ & $41,50 \mathrm{Aa}$ & $67,37 \mathrm{Ba}$ & $54,75 \mathrm{Aa}$ \\
\hline CD 215 & $69,50 \mathrm{Aa}$ & $35,63 \mathrm{Ab}$ & $84,88 \mathrm{Aa}$ & $44,88 \mathrm{Ab}$ \\
\hline CD 216 & $74,00 \mathrm{Aa}$ & $36,00 \mathrm{Ab}$ & $90,38 \mathrm{Aa}$ & $44,38 \mathrm{Ab}$ \\
\hline \multicolumn{5}{|c|}{$30 / 09$} \\
\hline CD 202 & $66,75 \mathrm{Aa}$ & $47,75 \mathrm{Ab}$ & $78,50 \mathrm{Aa}$ & $56,38 \mathrm{Ab}$ \\
\hline CD 215 & $66,13 \mathrm{Aa}$ & $59,13 \mathrm{Aa}$ & $79,88 \mathrm{Aa}$ & $66,88 \mathrm{Aa}$ \\
\hline CD 216 & $59,13 \mathrm{Aa}$ & $59,13 \mathrm{Aa}$ & $67,88 \mathrm{Aa}$ & $68,00 \mathrm{Aa}$ \\
\hline \multicolumn{5}{|c|}{$15 / 10$} \\
\hline CD 202 & $65,25 \mathrm{Aa}$ & $52,00 \mathrm{Aa}$ & $78,63 \mathrm{Aa}$ & $62,50 \mathrm{Ab}$ \\
\hline CD 215 & $75,00 \mathrm{Aa}$ & $55,75 \mathrm{Ab}$ & $85,00 \mathrm{Aa}$ & $65,50 \mathrm{Ab}$ \\
\hline CD 216 & $47,63 \mathrm{Ba}$ & $43,63 \mathrm{Aa}$ & $61,13 \mathrm{Ba}$ & $53,25 \mathrm{Aa}$ \\
\hline \multicolumn{5}{|c|}{$30 / 10$} \\
\hline CD 202 & $41,50 \mathrm{Bb}$ & $75,50 \mathrm{Aa}$ & $55,88 \mathrm{Bb}$ & $82,25 \mathrm{Aa}$ \\
\hline CD 215 & $62,38 \mathrm{Aa}$ & $61,13 \mathrm{Aa}$ & $71,75 \mathrm{Aa}$ & $71,50 \mathrm{Aa}$ \\
\hline CD 216 & $64,63 \mathrm{Aa}$ & $63,13 \mathrm{Aa}$ & $76,25 \mathrm{Aa}$ & $72,63 \mathrm{Aa}$ \\
\hline \multicolumn{5}{|c|}{$15 / 11$} \\
\hline CD 202 & $13,00 \mathrm{Ba}$ & $18,75 \mathrm{Ba}$ & $24,00 \mathrm{Ba}$ & $22,63 \mathrm{Ba}$ \\
\hline CD 215 & $9,50 \mathrm{Ba}$ & $20,88 \mathrm{Ba}$ & $31,00 \mathrm{Ba}$ & $28,88 \mathrm{Ba}$ \\
\hline CD 216 & $36,44 \mathrm{Aa}$ & $44,38 \mathrm{Aa}$ & $70,63 \mathrm{Aa}$ & $51,50 \mathrm{Ab}$ \\
\hline C.V.(\%) & \multicolumn{2}{|c|}{18,48} & \multicolumn{2}{|c|}{15,29} \\
\hline
\end{tabular}

TABELA 2 - Resultados de vigor (1 - 3) e de viabilidade (1 - 5), obtidos no teste de tetrazólio das sementes de três cultivares de soja, produzidas em cinco épocas de semeadura, nos anos agrícolas de 2003/2004 e 2004/2005, em Palotina - PR.

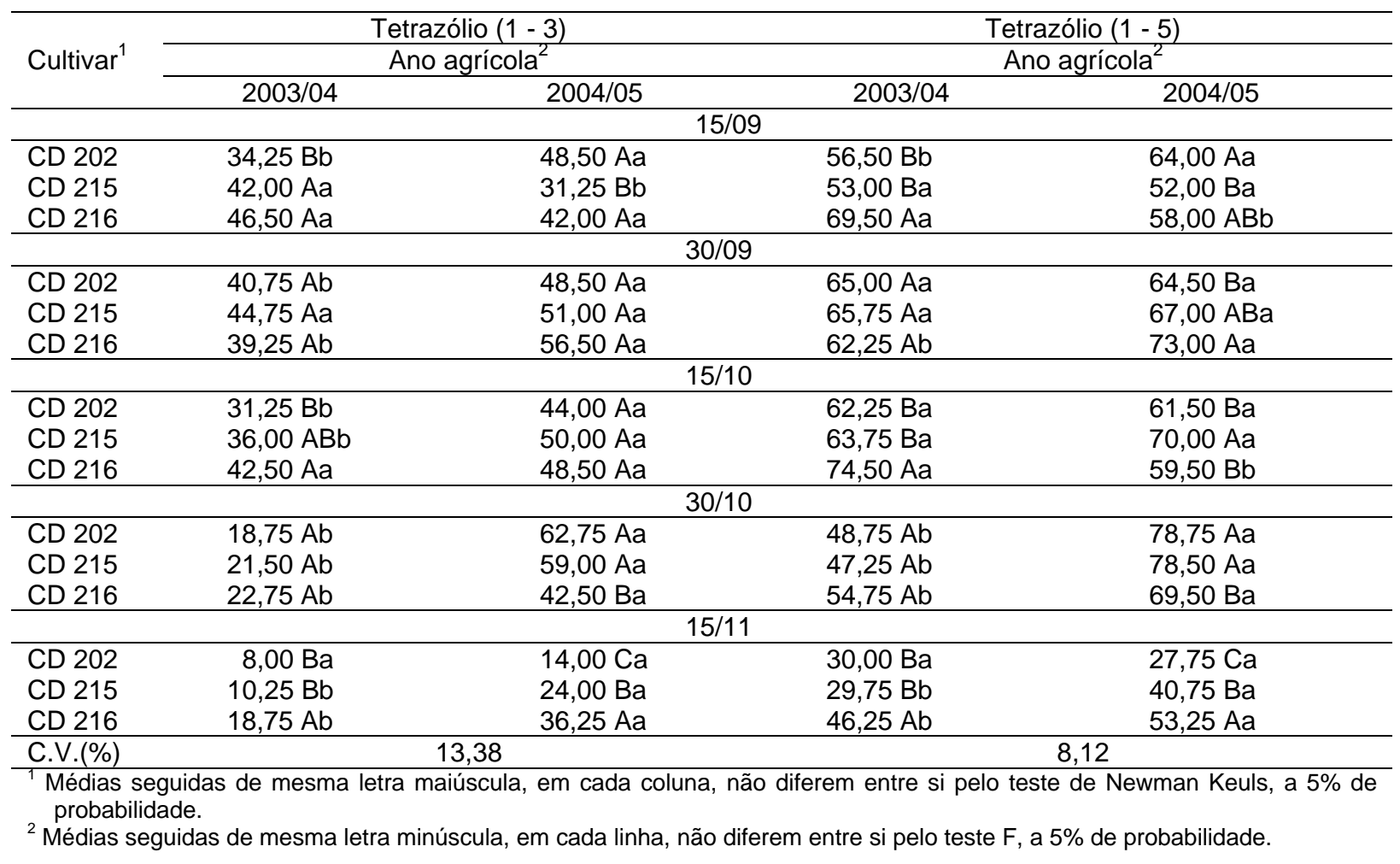


ALBRECHT, L.P. et al. Qualidade fisiológica e sanitária das sementes...

Em todos os testes realizados, as sementes da cultivar CD 216, na última época de semeadura, apresentaram resultados superiores em relação às demais, para os dois anos agrícolas avaliados. Esses resultados caracterizam uma possível vantagem da $C D 216$, que apresenta um ciclo mais curto, permitindo um escape de condições adversas no final do ciclo, quando comparada com as outras cultivares. Além de hábito de crescimento indeterminado, ampliando o período reprodutivo no sentido de parcelar e/ou prolongar a floração, propiciando, também, um escape das referidas condições climáticas. Além da rusticidade atribuída a cultivar (COODETEC, 2005). SPEARS et al. (1997) ao se referirem aos mecanismos de resistência à seca, sugerem que o padrão de crescimento indeterminado permite que essas cultivares sejam beneficiadas com a possível atenuação de condições de estresse.

A cultivar CD 202, na primeira época de semeadura do primeiro ano agrícola, não apresentou qualidade fisiológica superior em todos os testes. As sementes da cultivar CD 202 apresentaram também qualidade inferior às da $C D$ 215 e/ou CD 216, quando comparadas. O ciclo um pouco mais longo, expõe a CD 202 à precipitações ocorridas no segundo e terceiro decêndio de dezembro (Figura 1), juntamente com altas temperaturas e alta umidade, aceleraram 0 processo deteriorativo no final da maturação da cultivar, o que corrobora com a literatura (PAOLINELLI et al., 1984; COSTA et al., 1995; PEREIRA et al., 2000; MARCOS FILHO, 2005).

A primeira e a segunda safra, em sua maioria, demonstraram tendência quadrática para os testes de avaliação da qualidade fisiológica das sementes (Tabelas 3 e 4). Justifica-se, pois as cultivares precoces, por apresentarem um ciclo menor, são, em geral, mais exigentes, portanto, mais suscetíveis às condições de estresse, como a restrição hídrica.

TABELA 3 - Equações de regressão ajustadas para o efeito da interação Época/Ano x Cultivar e Época/Cultivar $x$ Ano, relativo aos testes de germinação (primeira contagem e contagem final) das sementes de três cultivares de soja, produzidas em cinco épocas de semeadura, no ano agrícola de 2003/2004 e 2004/2005, em Palotina - PR.

\begin{tabular}{|c|c|c|c|c|}
\hline \multicolumn{5}{|c|}{ Ano agrícola $2003 / 2004$} \\
\hline \multicolumn{5}{|c|}{ Primeira contagem de germinação (\%) } \\
\hline Cultivares & Equação & $\mathrm{R}^{2}$ & $\begin{array}{l}\text { Ponto de máximo } \\
\text { (dias após } 15 / 09)^{1}\end{array}$ & $\begin{array}{l}\text { Máximo da } \\
\text { função }(\%)^{2}\end{array}$ \\
\hline CD 202 & $Y=50,042+1,5441^{*} X-0,0365^{*} X^{2}$ & 0,99 & 21,15 & 66,37 \\
\hline CD 215 & $Y=64,036+1,4704^{*} X-0,0383^{*} X^{2}$ & 0,90 & 19,35 & 78,15 \\
\hline CD 216 & $Y=75,412-2,8197^{\star} X+0,1085^{\star} X^{2}-0,0012^{*} X^{3}$ & 0,84 & 35,10 & 58,90 \\
\hline \multicolumn{5}{|c|}{ Contagem final de germinação (\%) } \\
\hline Cultivares & Equação & $\mathrm{R}^{2}$ & $\begin{array}{l}\text { Ponto de máximo } \\
\text { (dias após 15/09) }^{1}\end{array}$ & $\begin{array}{l}\text { Máximo da } \\
\text { função }(\%)^{2}\end{array}$ \\
\hline CD 202 & $Y=67,619+1,2681^{*} X-0,0336 * X^{2}$ & 0,99 & 18,87 & 79,58 \\
\hline CD 215 & $Y=80,841+0,939 * X-0,0285^{\star} X^{2}$ & 0,93 & 16,47 & 88,58 \\
\hline CD 216 & $Y=91,076-3,0106^{*} X+0,0987^{*} X^{2}-0,0009^{*} X^{3}$ & 0,93 & 51,85 & 74,87 \\
\hline \multicolumn{5}{|c|}{ Ano agrícola 2004/2005 } \\
\hline \multicolumn{5}{|c|}{ Primeira contagem de germinação (\%) } \\
\hline Cultivares & Equação & $R^{2}$ & $\begin{array}{l}\text { Ponto de máximo } \\
\text { (dias após } 15 / 09)^{1}\end{array}$ & $\begin{array}{l}\text { Máximo da } \\
\text { função }(\%)^{2}\end{array}$ \\
\hline CD 202 & $Y=43,225-1,8236^{*} X+0,14 X^{2}-0,0019 X^{3}$ & 0,88 & 41,23 & 72,86 \\
\hline CD 215 & $Y=35,041+2,0784^{*} X-0,0377^{*} X^{2}$ & 0,88 & 27,56 & 63,69 \\
\hline CD 216 & $\mathrm{Y}=49,25$ & --- & -- & -- \\
\hline \multicolumn{5}{|c|}{ Contagem final de germinação (\%) } \\
\hline Cultivares & $\mathrm{C}$ & $\mathrm{R}^{2}$ & $\begin{array}{l}\text { Ponto de máximo } \\
\text { (dias após 15/09) }^{1}\end{array}$ & $\begin{array}{l}\text { Máximo da } \\
\text { função }(\%)^{2}\end{array}$ \\
\hline CD 202 & $Y=56,209-2,1887^{\star} X+0,1518^{*} X^{2}-0,0021 X^{3}$ & 0,92 & 42,86 & 75,91 \\
\hline CD 215 & $Y=43,595+2,1386^{*} X-0,0387^{*} X^{2}$ & 0,90 & 27,63 & 73,14 \\
\hline CD 216 & $\mathrm{Y}=57,95$ & --- & --- & --- \\
\hline
\end{tabular}


TABELA 4 - Equações de regressão ajustadas para o efeito da interação Época/Ano x Cultivar e Época/Cultivar $x$ Ano, relativo ao teste de tetrazólio $(1-3$ e $1-5)$ das sementes de três cultivares de soja, produzidas em cinco épocas de semeadura, nos anos agrícolas de 2003/2004 e 2004/2005, em Palotina - PR.

\begin{tabular}{|c|c|c|c|c|}
\hline \multicolumn{5}{|c|}{ Ano agrícola $2003 / 2004$} \\
\hline \multicolumn{5}{|c|}{ Tetrazólio $1-3(\%)$} \\
\hline Cultivares & Equação & $\mathrm{R}^{2}$ & 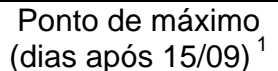 & $\begin{array}{l}\text { Máximo da } \\
\text { função }(\%)^{2}\end{array}$ \\
\hline CD 202 & $Y=6,143+0,2176^{*} X-0,0119^{*} X^{2}$ & 0,95 & 9,14 & 37,14 \\
\hline CD 215 & $Y=43,429+0,0645^{*} X-0,0107^{*} X^{2}$ & 0,97 & 3,01 & 43,53 \\
\hline CD 216 & $\mathrm{Y}=48,35-0,48^{*} \mathrm{X}$ & 0,84 & --- & --- \\
\hline \multicolumn{5}{|c|}{ Tetrazólio $1-5(\%)$} \\
\hline Cultivares & Equação & $\mathrm{R}^{2}$ & $\begin{array}{l}\text { Ponto de máximo } \\
\text { (dias após 15/09) }\end{array}$ & $\begin{array}{l}\text { Máximo da } \\
\text { função }(\%)^{2}\end{array}$ \\
\hline CD 202 & $\mathrm{Y}=57,029+0,7812^{*} \mathrm{X}-0,0207^{*} \mathrm{X}^{2}$ & 1,0 & 18,87 & 64,40 \\
\hline CD 215 & $Y=54,186+0,9952 * X-0,0238^{*} X^{2}$ & 0,97 & 20,91 & 64,58 \\
\hline CD 216 & $Y=67,321+0,2971^{*} X-0,011^{*} X^{2}$ & 0,74 & 30,00 & 66,50 \\
\hline \multicolumn{5}{|c|}{ Ano agrícola 2004/2005 } \\
\hline \multicolumn{5}{|c|}{ Tetrazólio $1-3(\%)$} \\
\hline Cultivares & Equação & $\mathrm{R}^{2}$ & $\begin{array}{l}\text { Ponto de máximo } \\
\text { (dias após } 15 / 09)^{1}\end{array}$ & $\begin{array}{l}\text { Máximo da } \\
\text { função }(\%)^{2}\end{array}$ \\
\hline CD 202 & $Y=50,193-1,9607^{*} X+0,1164^{*} X^{2}-0,0016 X^{3}$ & 0,85 & 40,50 & 57,50 \\
\hline CD 215 & $Y=30,136+1,8519^{*} X-0,0316^{*} X^{2}$ & 0,82 & 29,30 & 57,27 \\
\hline CD 216 & $Y=44,607+0,5824^{\star} X-0,0125^{\star} X^{2}$ & 0,75 & 23,30 & 51,39 \\
\hline \multicolumn{5}{|c|}{ Tetrazólio 1-5 (\%) } \\
\hline Cultivares & Equação & $\mathrm{R}^{2}$ & $\begin{array}{l}\text { Ponto de máximo } \\
\text { (dias após 15/09) }\end{array}$ & $\begin{array}{l}\text { Máximo da } \\
\text { função }(\%)^{2}\end{array}$ \\
\hline CD 202 & $Y=65,604-1,9058^{*} X+0,1176^{*} X^{2}-0,0016 X^{3}$ & 0,87 & 38,75 & 75,24 \\
\hline CD 215 & $Y=49,564+1,8314^{\star} X-0,0317^{*} X^{2}$ & 0,80 & 28,89 & 76,02 \\
\hline CD 216 & $Y=62,65$ & --- & --- & --- \\
\hline
\end{tabular}

${ }^{*}$ Significativo a $5 \%$ de probabilidade pelo teste $t$

${ }^{1}$ Refere-se aos dias após 15/09 (primeira época de semeadura), em que há resposta máxima no potencial de vigor (tetrazólio de $1-3$ ) e no máximo potencial de viabilidade (tetrazólio de $1-5$ ).

${ }^{2}$ Concernente ao máximo potencial de vigor (tetrazólio de $1-3$ ) e ao máximo potencial de viabilidade (tetrazólio de 1 -5), correspondente ao ponto de máxima em dias após 15/09.

A tendência cúbica da cultivar CD 216 no primeiro ano agrícola, que foi em função de chuvas ocorridas em janeiro, que por mais que fossem escassas, coincidiram, pontualmente, com a pós-maturação fisiológica e pré-colheita. Isso levou a cultivar CD 216 a apresentar um decréscimo na qualidade fisiológica de suas sementes, quando a semeadura ocorreu entre a segunda e terceira épocas do referido ano agrícola. No entanto, os seus pontos de máximo variando de 30 à 52 dias após a primeira época de semeadura (15/09) denotam a maior tolerância da CD 216 à estiagem, observada para as semeaduras em época preferencial.

A equação linear ajustada para a cultivar CD 216, no primeiro ano agrícola, para a variável potencial de vigor $(1-3)$ no teste de tetrazólio, indicou um decréscimo no potencial de vigor em função do atraso na semeadura. Este comportamento reflete bem a condição de estresse hídrico ocorrida naquele ano agrícola, particularmente para as épocas de semeadura mais tardias. Semeaduras em diferentes épocas, as cultivares expressam suas potencialidades em relação às condições do ambiente, que mudam no espaço e no tempo. (PAOLINELLI et al., 1984; BARROS et al., 2003; PELÚZIO et al., 2006).
Os pontos de máximo para as cultivares CD 202 e CD 215, no primeiro ano agrícola (2003/ 2004), estiveram, em sua maioria, situados entre 9 e 21 dias após 15/09. Os resultados indicaram que a antecipação da semeadura para próximo de 15/ 09 e a semeadura na época preferencial, novembro (EMBRAPA, 2003), foram menos favoráveis a obtenção de sementes de melhor qualidade fisiológica na referida região. No segundo ano agrícola, mais evidente que no primeiro, os resultados indicaram que não só a época preferencial (15/11), mas a primeira época de semeadura (15/09) não proporcionaram a obtenção de sementes com qualidade elevada, uma vez que a maioria das respostas, quando significativas, foram quadráticas.

Em relação à qualidade sanitária das sementes, avaliando a incidência das espécies e/ ou gênero dos fungos Aspergillus spp., Cercospora kikuchii, Colletotrichum dematium, Fusarium semitectum e Phomopsis spp., nas sementes, foram observadas diferenças significativas $(P<0,05)$ apenas na primeira e quinta épocas de semeadura, entre os anos agrícolas avaliados (Tabela 5), para total de fungos. Na primeira época de semeadura, a cultivar CD 202 na safra 2003/2004, e a cultivar CD 
ALBRECHT, L.P. et al. Qualidade fisiológica e sanitária das sementes...

215 na safra 2004/2005, apresentaram a maior porcentagem no total de fungos nas sementes, com destaque para os fungos Fusarium semitectum e Phomopsis spp. A maior incidência de fungos pode ter sido a causa de problemas no desempenho das sementes em termos de qualidade fisiológica, concordando com FRANÇA NETO e HENNING (1992), PAOLINELLI et al. (1984), PEREIRA et al. (2000) e MARCOS FILHO (2005).

TABELA 5 - Porcentagem total de fungos, obtida no teste de sanidade das sementes de três cultivares de soja, produzidas em cinco épocas de semeadura, nos anos agrícolas de 2003/2004 e 2004/2005, em Palotina - PR.

\begin{tabular}{|c|c|c|}
\hline \multirow{3}{*}{ Cultivar $^{1}$} & \multicolumn{2}{|c|}{ Total de fungos } \\
\hline & \multicolumn{2}{|c|}{ Ano agrícola ${ }^{2}$} \\
\hline & $2003 / 04$ & $2004 / 05$ \\
\hline \multicolumn{3}{|c|}{$15 / 09$} \\
\hline CD 202 & $61,00 \mathrm{Aa}$ & $43,25 \mathrm{Ab}$ \\
\hline CD 215 & $23,50 \mathrm{Bb}$ & $45,50 \mathrm{Aa}$ \\
\hline CD 216 & $27,75 \mathrm{Ba}$ & $44,25 \mathrm{Aa}$ \\
\hline \multicolumn{3}{|c|}{$30 / 09$} \\
\hline CD 202 & $33,25 \mathrm{Aa}$ & $18,25 \mathrm{Ba}$ \\
\hline CD 215 & $13,00 \mathrm{Ba}$ & $22,50 \mathrm{Ba}$ \\
\hline CD 216 & $47,25 \mathrm{Aa}$ & $53,75 \mathrm{Aa}$ \\
\hline \multicolumn{3}{|c|}{$15 / 10$} \\
\hline CD 202 & $41,75 \mathrm{Aa}$ & $28,50 \mathrm{Ba}$ \\
\hline CD 215 & $38,00 \mathrm{Aa}$ & $32,75 \mathrm{Ba}$ \\
\hline CD 216 & $45,25 \mathrm{Aa}$ & $52,75 \mathrm{Aa}$ \\
\hline \multicolumn{3}{|c|}{$30 / 10$} \\
\hline CD 202 & $23,50 \mathrm{Aa}$ & $36,25 \mathrm{Aa}$ \\
\hline CD 215 & $22,00 \mathrm{Aa}$ & $30,50 \mathrm{Aa}$ \\
\hline CD 216 & $16,81 \mathrm{Aa}$ & $31,00 \mathrm{Aa}$ \\
\hline \multicolumn{3}{|c|}{$15 / 11$} \\
\hline CD 202 & $32,00 \mathrm{Ab}$ & $59,50 \mathrm{Aa}$ \\
\hline CD 215 & $30,25 \mathrm{Aa}$ & $43,25 \mathrm{ABa}$ \\
\hline CD 216 & $20,00 \mathrm{Ab}$ & $39,25 \mathrm{Ba}$ \\
\hline C.V.(\%) & \multicolumn{2}{|c|}{32,78} \\
\hline
\end{tabular}

Observando a Tabela 5, pode-se notar um maior percentual total de fungos nas sementes da cultivar CD 202, em relação às outras cultivares, na primeira época da safra 2003/2004. Na quinta época de semeadura do segundo ano agrícola (2004/ 2005), a cultivar CD 202 foi de sanidade inferior a CD 216. Os piores resultados de sanidade estiveram relacionados com a menor porcentagem de plântulas normais no teste de germinação (Tabela 1). A cultivar CD 202, apresenta tegumento menos resistente, em virtude do baixo teor de lignina (ALVAREZ, 1994), o que lhe confere menor tolerância a danos, como o mecânico, e a infecção por patógenos.

$\mathrm{Na}$ Tabela 6 o aumento na porcentagem de fungos na quinta época de semeadura, para as sementes da cultivar CD 202, na segunda safra (2004/2005), pode ser explicado pelo relato de MACHADO (1988), que menciona o baixo vigor de sementes, decorrente de fatores não infecciosos (como o estresse hídrico), como um fator de predisposição das sementes à ação mais severa de patógenos avaliados.
Deste modo, a ocorrência de temperaturas elevadas e alta precipitação pluvial nos últimos estádios da cultura podem acelerar o processo de deterioração, enquanto, altas temperaturas e limitação hídrica ocasionam desenvolvimento inadequado das sementes; assumindo relevância na determinação da qualidade das sementes, diante das épocas de semeadura. Afirmativa que condiz com os resultados e, de acordo com vários autores (PAOLINELLI et al., 1984; COSTA et al., 1995; PEREIRA et al., 2000; MARCOS FILHO, 2005)

\section{CONCLUSÕES}

Nas condições do presente estudo, a antecipação na semeadura e a época preferencial não são propícios à obtenção de sementes com melhor desempenho fisiológico, para cultivares de ciclo precoce, em Palotina - Paraná. 
TABELA 6 - Equações de regressão ajustadas para o efeito da interação Época/Ano x Cultivar e Época/Cultivar $x$ Ano, relativo ao teste de sanidade das sementes de três cultivares de soja, produzidas em cinco épocas de semeadura, nos anos agrícolas de 2003/2004 e 2004/2005, em Palotina - PR.

\begin{tabular}{|c|c|c|c|c|}
\hline \multicolumn{5}{|c|}{ Ano agrícola $2003 / 2004$} \\
\hline \multicolumn{5}{|c|}{ Sanidade (\%) } \\
\hline Cultivares & Equação & $\mathrm{R}^{2}$ & $\begin{array}{l}\text { Ponto de mínimo } \\
\text { (dias após 15/09) }^{1}\end{array}$ & $\begin{array}{l}\text { Mínimo da } \\
\text { função }(\%)^{2}\end{array}$ \\
\hline CD 202 & $Y=58,386-1,3231^{*} X+0,0145^{*} X 2$ & 0,75 & 45,62 & 32,15 \\
\hline CD 215 & $Y=25,35$ & --- & --- & --- \\
\hline CD 216 & $Y=26,85+3,357^{*} X-0,1368^{*} X^{2}+0,0013 X^{3}$ & 0,74 & 54,48 & 13,92 \\
\hline \multicolumn{5}{|c|}{ Ano agrícola 2004/2005 } \\
\hline \multicolumn{5}{|c|}{ Sanidade (\%) } \\
\hline Cultivares & Equação & $\mathrm{R}^{2}$ & $\begin{array}{l}\text { Ponto de mínimo (dias } \\
\text { após } 15 / 09)^{1}\end{array}$ & $\begin{array}{l}\text { Mínimo da } \\
\text { função }(\%)^{2}\end{array}$ \\
\hline CD 202 & $Y=40,479-1,4538^{*} X+0,0298^{*} X^{2}$ & 0,91 & 24,39 & 22,75 \\
\hline CD 215 & $\mathrm{Y}=34,90$ & --- & --- & --- \\
\hline CD 216 & $Y=44,20$ & --- & --- & --- \\
\hline
\end{tabular}

* Significativo a $5 \%$ de probabilidade pelo teste t.

${ }^{1}$ Refere-se aos dias após 15/09 (primeira época de semeadura), em que há resposta máxima no percentual total de fungos.

${ }^{2}$ Concernente à máxima porcentagem total de fungos, correspondente ao ponto de máximo em dias após 15/09.

\section{REFERÊNCIAS}

1. ALVAREZ, P.J. Relação entre o conteúdo de lignina no tegumento de sementes de soja e sua relação ao dano mecânico. 1994. 43f. Dissertação (Mestrado em Agronomia) - Universidade Estadual de Londrina, Londrina, 1994.

2. BARROS, H. B.; PELUZIO, J. M.; SANTOS, M. M.; BRITO, E. L.; ALMEIDA, R. D. Efeitos das épocas de semeadura no comportamento de cultivares de soja, no sul do Estado do Tocantins. Revista Ceres, v. 50, n. 291, p. 565-572, 2003.

3. BERGAMIN, M.; CANCIAN, M.A.E.; CASTRO, P.R.C. Ecofisiologia da soja. In: CASTRO, P.R.C.; KLUGE, R.A. (Ed.). Ecofisiologia de cultivos anuais: trigo, milho, soja, arroz e mandioca. São Paulo: Nobel, 1999. p. 73-90.

4. BERLATO, M.A.; FONTANA, D.C. Variabilidade interanual da precipitação pluvial e rendimento da soja no estado do Rio Grande do Sul. Revista Brasileira de Agrometeorologia, v. 7, n. 1, p. 119-125, 1999.

5. BHÉRING, M.C.; REIS, M.S.; SEDIYAMA, C.S.; SEDIYAMA, T.; ANDRADE, M.A.S. Influência de épocas de plantio sobre a qualidade fisiológica das sementes de soja (Glycine max (L.) Merrill). Revista Ceres, v. 38, n. 219, p. 409-421, 1991.

6. BONATO, E. R.; BERTAGNOLLI, P. F.; IGNACZAK, J. C.; TRAGNAGO, J. L.; RUBIN, S. A. L. Desempenho de cultivares de soja em três épocas de semeadura, no Rio Grande do Sul. Pesquisa Agropecuária Brasileira, v. 33, n. 6, p. 879-884, 1998.

7. BRADFORD, K. Water stress and the water relations of seed development: a critical review. Crop Science, v. 34, n. 1, p. 1-11, 1994.

8. BRASIL. Ministério da Agricultura e Reforma Agrária. Regras para análise de sementes. Brasília: DNDV/SNAD/CLAV, 1992. 365p.

9. BRASIL. Instrução Normativa n. 25, de 16 de dezembro de 2005: Padrões para produção e comercialização de sementes de soja. Diário Oficial da União, n. 243 de 20 de dezembro de 2005, Brasília, DF, 20 de dezembro de 2005. Seção 1, p.2.

10. COODETEC - Cooperativa Central de Pesquisa Agrícola. Prospecto técnico de cultivares. Cascavel: COODETEC, 2005.

11. COSTA, N.P.; PEREIRA, L.A.G.; FRANÇA NETO, J. de B.; HENNING, A.A.; KRZYZANOWSKI, F.C. Zoneamento ecológico do Estado do Paraná para a produção de sementes de cultivares precoces de soja. Revista Brasileira de Sementes, v. 16, n. 1, p. 12-19, 1994.

12. COSTA, N.P.; FRANÇA NETO, J.B.; HENNING, A.A.; KRZYZANOWSKI, F.C.; CABRAL, N.T.; MENDES, M.C. Efeito da época de semeadura sobre a qualidade fisiológica de sementes de soja no Estado do Mato Grosso. Revista Brasileira de Sementes, v. 17, n. 1, p. 107-112, 1995.

13. CRUZ, C.D.; REGAZZI, A.J.; CARNEIRO, P.C.S. Modelos biométricos aplicados ao melhoramento genético. 3. ed. Viçosa: UFV, 2004. p. 50-101.

14. EMBRAPA. Tecnologias de produção de soja - Paraná - 2003/04. Londrina: Embrapa/CNPSo, 2003. 218p. (Sistemas de Produção, 3).

15. FEHR, W.R.; CAVINESS, C.E.; GURMOOD, D.T.; PENNINGTON, J.S. Stage of development description for soybean, Glycine $\max ($ L.) Merrill. Crop Science, v. 11, n. 6, p. 929-931, 1971.

16. FRANÇA NETO, J. de B.; HENNING, A.A. DIACOM: diagnóstico completo da qualidade da semente de soja. Londrina : Embrapa-CNPSo, 1992. 21p. (Embrapa-CNPSo. Circular Técnica, 10).

17. FRANÇA NETO, J.B.; KRZYZANOWSKI, F.C.; HENNING, A.A.; WEST, S.H.; MIRANDA, L.C. Soybean seed quality as affected by shiveling due to heat and drought stress during seed filling. Seed Science and Technology, v. 21, n. 1, p. 107-116, 1993.

18. FRANÇA NETO, J.B.; KRZYZANOWSKI, F.C.; COSTA, N.P. O teste de tetrazólio em sementes de soja. Londrina: EMBRAPA-CNPSo, 1998. 72p. (Documentos, 116).

19. GOULART, A.C.P. Fungos em sementes de soja: detecção e importância. Dourados: Embrapa/CPAO, 1997. 58p. (Documentos, 11). 
ALBRECHT, L.P. et al. Qualidade fisiológica e sanitária das sementes...

20. IAPAR. Instituto Agronômico do Paraná. Clima do Paraná. Disponível em: <http://www.iapar.br/>. Acesso em: 19 jul. 2006.

21. MACHADO, J.C. Patologia de sementes: significado e atribuições. In: CARVALHO, N.M.; NAKAGAWA, J. (Ed.). Sementes: Ciência, tecnologia e produção. 3 ed. Campinas: Fundação Cargill, 1988. 424p.

22. MARCOS FILHO, J. Fisiologia de sementes de plantas cultivadas. Piracicaba: Fealq, 2005. 495p.

23. MATZENAUER, R.; BARNI, N.A.; MALUF, J.R.T. Estimativa do consumo relativo de água para a cultura da soja no Estado do Rio Grande do Sul. Ciência Rural, v. 33, n. 6, p. 1013-1019, 2003.

24. MATZENAUER, R.; CARGNELUTTI FILHO, A.; BARNI, N.A.; MALUF, J.R.T.; RADIN, B.; ANJOS, C.S. Época de semeadura para milho e soja visando à redução de risco por deficiência hídrica, no Rio Grande do Sul. Revista Brasileira de Agrometeorologia, v. 13, n. 2, p. 191-200, 2005.

25. MOTTA, I.S.; BRACCINI, A.L.; SCAPIM. C.A; INOUE M.H.; ÁVILA, M.R.; BRACCINI, M.C.L. Época de semeadura em cinco cultivares de soja. I. Efeito nas características agronômicas. Acta Scientiarum. Agronomy, v. 24, n. 5, p. 1275-1280, 2002.

26. PAOLINELLI, G.P.; TANAKA, M.A.S.; REZENDE, A.M. Influência da época de semeadura sobre a qualidade fisiológica e sanitária de sementes de soja. Revista Brasileira de Sementes, v. 6, n. 1, p. 39-50, 1984.

27. PEIXOTO, C.P.; CÂMARA, G.M.S.; MARTINS, M.C.; MARCHIORI, L.F.S.; GUERZONI, R.A.; MATTIAZZI, P. Sowing date and plant density of soybean: I. Yield components and grain yield . Scientia Agricola, v. 57, n. 1, p. 153-162, 2000.

28. PELÚZIO, J.M.; FIDELIS, R.R.;ALMEIDA JÚNIOR, D.; BARBOSA, V.S.; RICHTER, L.H.M; Rubens Ribeiro da SILVA5;AFFÉRRI, F.S. Desempenho de cultivares de soja, em duas épocas de semeadura, no sul do estado do tocantins. Bioscience Journal, v. 22, n. 2, p. 69-74, 2006.

29. PEREIRA, E.B.C.; PEREIRA, A.V.; FRAGA, A.C. Seed quality of early maturing soybean cultivars from different sowing dates. Pesquisa Agropecuária Brasileira, v.35, n. 8, p. 1653-1662, 2000.

30. PIMENTEL-GOMES, F.; GARCIA, C.H. Estatística aplicada a experimentos agronômicos e florestais: exposição com exemplos e orientação para uso de aplicativos. Piracicaba: Fealq, 2002. 309p.

31. SILVA, J.B.; LAZARINI, E.; SÁ, M.E. Evaluation of soybean cultivars in winter sowing, in Selvíria, MS, Brazil: production and physiological quality of seeds. Revista Brasileira de Sementes, v. 29, n. 3, p.189-196, 2007

32. SPEARS, J.F.; TEKRONY, D.M.; EGLI, D.B. Temperature during seed filling and soybean seed germination. Seed Science and Technology, v. 25, n.2, p.233-244, 1997.

33. TAIZ, L.; ZEIGER, E. Trad.: SANTARÉM, E.R. Fisiologia vegetal. Porto Alegre: Artmed, 2004. 613p.

Recebido em 11/04/2008

Aceito em 12/08/2008 
